PAPER

\title{
Advanced and end of life care: cautionary suggestions
}

\author{
F M Kamm
}

Harvard University, USA

Correspondence to

Professor F M Kamm;

frances_kamm@harvard.edu

Received 4 October 2016 Revised 30 December 2016 Accepted 6 January 2017 Published Online First

7 February 2017

\section{SLinked}

- http://dx.doi.org/10.1136/ medethics-2017-104142 - http://dx.doi.org/10.1136/ medethics-2017-104143 - http://dx.doi.org/10.1136/ medethics-2017-104436 - http://dx.doi.org/10.1136/ medethics-2017-104470

\section{CrossMark}

To cite: Kamm FM.

$J$ Med Ethics

2017;43:577-586.

\section{ABSTRACT}

This article consider some clinical and population level approaches to advanced care of chronic conditions and end of life care. One approach aims to follow patient values and preferences about acceptable end of life (EOL) as elicited by questionnaires. The grounds for emphasising patients' preferences and the adequacy of the questionnaires are examined. Other approaches involve additional aims such as meeting patient and family members needs, providing information, cost effectiveness and satisfying professionals' preferences for a certain type of EOL experience. Issues raised by adding these (and other) aims are examined.

In this article, I consider some recent views about advanced care (AC) and end of life care (EOLC). The former involves care of those who have 'advanced illness' involving 'multiple chronic conditions with declining function and poor prospects for full recovery'. 'Many established advanced care models seek to include people...that may be two to three years from end of life. A common goal...is to provide...care at a stage that is sufficiently "upstream" from end of life....to significantly improve quality of life and to help avoid unnecessary acute spells and accidents resulting in hospitalization or emergency room use'. ${ }^{2}$ As such, $\mathrm{AC}$ is an attempt to prevent persons from becoming patients in many cases. EOLC deals with people much closer to death (often identified in studies by a physician saying she would 'not be surprised' if the person died within the next year). While some refer to care in this period as helping people to die well, it is now common to speak of helping them to live a life acceptable to them until death.

The views I consider are represented in several public documents whose contents I will critically examine. In section I, I focus on the report and recommendations of the Massachusetts Panel on EOLC entitled 'Patient-Centered Care and Human Mortality'3 (henceforth 2010), while also considering positions taken by The Conversation Project (henceforth TCP) ${ }^{4}$ and in a report of the Coalition to Transform Advanced Care (henceforth C-TAC). The focus of both TCP and C-TAC is on reaching people who are not yet and who may never become patients (if they decide to decline medical treatments). So these projects may be considered population based rather than clinical projects. This contrasts with 2010's focus on patients. In section II, I consider a particular way in which some recommendations like 2010's are made concrete by TCP and in a study conducted by members of Beth
Israel Hospital in Boston (henceforth 2015). ${ }^{5}$ In section III, I conclude by considering a study entitled 'Peace, Equanimity, and Acceptance in the Cancer Experience (PEACE)' (henceforth PEACE), ${ }^{6}$ which is cited in 2015 .

Overall, I argue: (1) While professionals involved in AC and EOLC typically begin with calls to attend to preferences of a person (who may or may not yet be a patient) to be provided with care, they seem to have aims beyond guiding care according to those preferences and view these aims as having objective value. In particular, while a ground given for attending to patients' preferences is that views on what constitutes a good death vary, many professionals have a particular view of what a good death is and hope to promote it for what they see as patients' own good. Having such aims is not necessarily wrong but it is worth bringing it out clearly for the sake of full disclosure, and also because conflicts could arise between those aims and patients' preferences. (2) The way in which some of the documents I will consider attempt to elicit a person's preferences may involve 'nudging' and 'framing effects' that could produce skewed or biased results that prevent reliably eliciting preferences. (3) Professionals show markedly different views on whether persons must be well informed. Those who put least emphasis on it may find that it conflicts with patients achieving the sort of EOLC professionals think best and leads to a greater role for professional's EOLC recommendations because of their superior knowledge. (4) Increasingly higher standards for a life before death that is acceptable to persons may be in tension with refusal by many EOLC professionals to support the option of assisted suicide.

This article has the limited focus of providing a philosophical perspective on the documents. I attend to whether they are consistent, contain logical gaps and how the issues they deal with are connected with some problems dealt with by philosophers. It is not meant to describe my own views about many of the issues. Far from denying the importance and merit of the aims of professionals involved in AC and EOLC, one aim of this article is to be useful to such professionals by identifying potential pitfalls of the current approaches and providing suggestions to address them. Another aim is to suggest, by examining some documents, that philosophers might play a useful role during the process that produces official reports and research results. An additional benefit of examining these particular documents is that to a significant degree they are the work of an overlapping group of 
physicians and researchers ${ }^{\mathrm{i}}$ and so it may be possible to track some developments in an intellectual community.

\section{SECTION I}

\section{A. Preferences, well-informed choices and needs}

2010 begins (in its introduction, henceforth Intro) by noting that people have varying views on how best to deal with death and dying. ${ }^{\text {ii }}$ This is the fundamental reason it gives for emphasising 'patient-centred' care; that is, care 'anchored in the patient's own values and preferences' and goals (Intro). ${ }^{\text {iii }}$ Another fundamental concern of 2010 is that patients 'be supported in making well-informed choices among the full range of options for their care-whether aggressively life-prolonging, or entirely comfort-based or some balance of the two' (Intro). It says 'For some people, end-of-life care will include the use of advanced medical technology that attempts to extend life even if the burdens of treatments increase and the odds of success diminish. Others...prioritize comfort...many will choose aspects of both, varying over the course of their illness' (p. 2). It claims that well-informed patient-centred care would 'improve end of life care' (p. 2) and 'enable individuals to retain as much control as possible over their end of life experience...a good death according to their own definition' (p. 29). ${ }^{\text {iv }} 2010$ seems to emphasise cognitive awareness of prognosis and options as playing an important role in this improvement.

What prompts the report is concern that patients as of 2010 were not getting such a 'patient-centred' end of life (EOL) experience. 2010 notes that $70 \%$ of Americans say that they want to die at home yet $70 \%$ die in hospital (pp. 1-2). ${ }^{\mathrm{v}}$ However, 2010 goes on to interpret this expressed desire to die at home, "When people say they "want to die at home", almost all have more in mind than the physical location of their last breath' (p. 2). Hence, in going on to describe what it believes people actually want and what the report is concerned that they are not getting, 2010 says (in part), 'Regardless of their care setting, what people want and need at the end of life...that their wishes and values are respected, that their symptoms are well controlled, that their dignity is maintained, and that they can spend as much meaningful time as possible with those they most love' (p. 2). It also says 'Some...undergo more intensive medical interventions than they want, some less...Too often there is a mismatch between what they want and what they get' (p. 3). Notice that the idea of a mismatch is neutral as to the content of their preferences; it does not refer to specifics such as symptom control and meaningful time with loved ones as the earlier quote does.

\footnotetext{
${ }^{\mathrm{i} O n}$ this see footnote $\mathrm{xv}$.

ii The Conversation Project (TCP) says: 'Don't judge: A "good" death means different things to different people' (p. 9).

iii2 2010 does not rely on more fundamentally rights-based reasons for emphasising patients' preferences. Note that 'person-centred' is now preferred by many to 'patient-centred'. See Petrie-Flom/C-TAC Conference on Advanced Care and Health Policy "Aligning Policy and People: Why the Time is Right to Transform Advanced Care" (henceforth Petrie-Flom/C-TAC Conference) video; accessed July/2016 at http://petrieflom.law.harvard.edu/events/details/aligning-policy-andpeople). However, I will use 2010's locution in discussing 2010.

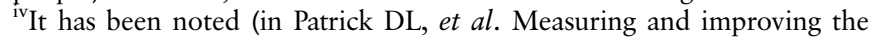
quality of dying and death. Ann Internal Med 2003;139:410-15) that quality of EOLC, EOL quality and quality of death itself should be distinguished. (However, I will often follow a document's use of terms even when they do not distinguish these.)

${ }^{\mathrm{v}}$ It would be useful to know when people say they want to die at home since 2010 notes that preferences may change over time. Later
}

\section{B. Possible conflicts among preferences, objectives goods and well-informed consent}

The 2010 paragraph quoted above shows, I believe, that 2010 is concerned with more than what patients want. First, the paragraph is also concerned with what patients need. One could need something one does not want and one could want something that one does not need. Furthermore, needs are usually thought of as being determined on more objective grounds (or are intersubjectively agreed to be reasonable), unlike wants and preferences, which need not be reasonable. ${ }^{\text {vi }} 2010$ might be concerned with the overlap of wants and needs but this is not clear.

Second, the quoted paragraph seems to list control of symptoms, maintenance of dignity and spending meaningful time with loved ones both as the objects of people's preferences and as goods separate from and in addition to satisfying people's preferences. If they are considered goods independent of being preferred by patients, achieving them may be an additional standard to be met in determining whether EOLC and quality of EOL is good. These factors all have to do with the patient's well-being or status but they are outside of 'patient centeredness', which (as used in 2010) does not refer to concern with patients' well-being or status in general but to being 'anchored in the patient's own values and preferences' (Intro).

Third, there are other grounds for thinking that in addition to satisfying patients' preferences, 2010 is concerned with more objective measures of improving EOLC and experience. For example, it says well-informed consent requires that 'evidencebased best practices' (p. 19) be among the options from which patients choose. Also, 'Because palliation provides proven benefit (by measure of longer life, better time alive, etc.) [it] should be included as an option' (p. 4). It goes on to say that given these proven benefits, a choice 'cannot be considered wellinformed...unless [patients] have...understanding, as early...as possible' (p. 4) of palliative care as an option, and for 'choices to be well informed...[patients] must understand what hospice offers' (p. 5). ${ }^{\text {vii }}$ There is also mention that these options include spiritual support (eg, see Executive Summary).

It seems then that for EOLC to improve by being driven by patients' own choices, the choices must be well informed. This means that there is certain information with respect to best practices that patients 'must' have (p. 4) whether they want the information or not. This is not an unreasonable view but it would be good for it to be made clear since it goes beyond doing what patients prefer, which might be interpreted to imply following their preferences about whether to receive full information. (The latter position is taken in 2015 and in TCP, as we shall see.) Indeed, 2010 goes so far as to say that 'payment for medical services requires adequate documentation that they are based on the well-informed wishes of patients (or appropriate surrogates) including understanding of life-prolonging and palliative care or hospice alternatives' (p. 23). Hence, 2010 touches on an important and disputed philosophical issue about whether well-informed consent is an option that patients have a right to exercise or more like a duty that patients must perform.

vithis is consistent with objectively determining whether preferences are
satisfied and with it being an objective good that they are. It is just that
the object of the preference (what is preferred) may not be objectively
reasonable.
viiPalliation and hospice differ. Palliation can be offered at any time
during any illness; hospice is care once EOL is expected though the
report also recommends it start much earlier than it does now for 
Despite its emphasis on full information about options, 2010 never mentions physician-assisted suicide (PAS), available in some areas of the USA and foreign countries, as something about which patients should be informed. Though PAS is not offered in Massachusetts, it remains an option as some patients move residence to acquire PAS. ${ }^{\text {viii }}$ I shall return to this issue below.

\section{Possible conflicts between preferences and 'best practice' standards}

Conflicts might also be generated between 2010's (1) commitment to some choosing 'medical technology that attempts to extend life even if the burdens of treatment increase and the odds of success diminish' (p. 2) along with its insistence that ' $[\mathrm{n}] \mathrm{o}$ patient is forced to decline life-prolonging measures in order to receive palliative care services that enhance quality of life' (p. 23) and (2) its claim that '[f]rom time of diagnosis...the central responsibility of health providers... is to help ensure that patients and their loved ones make the most of whatever amount of time it is possible for them to have together' (pp. 11-12). Point (2) suggests that the focus is on quality of life and that may conflict with increasing burdens of treatments allowed in point (1). 2010 describes a palliative care physician saying to patients that 'Your oncology team is in charge of helping you live as long as possible. I am in charge of helping you live as well as possible. And we are working together' (p. 12). However, living 'as long as possible' may be inconsistent with living 'as well as possible' and more likely there will be compromises with one or both goals. 2010's claim that 'if an acceptable quality of life can be achieved, most patents will then of course want longer life in that condition' (p. 12) seems to recognise that 'acceptable quality' need not be 'as well as possible'.

Most importantly, the standard of 'evidence-based best practices' that is used as grounds for including palliative and hospice care as options might not endorse the report's permission to pursue life-extending treatments that have 'marginal or no benefit' (p. 4) as 'the odds of success diminish' (p. 2). 2010 refers to a report that says about EOL medical treatments: 'the extra care does not produce better outcomes overall or result in better quality of care' (p. 14). So, it seems that 2010 does not require possibly life-extending medical treatments at EOL to meet a best practices standard it requires of palliation and hospice. On one hand, this exhibits willingness to allow people to go on resisting death and unwillingness to deny payment for such treatments while, on the other hand, it raises the question of why a standard of provable benefit used to judge the inclusion of some options should not be used to judge them all.

\section{Possible conflicts between patient's preference/needs and family preference/needs}

The measures of improved care in 2010 that we have considered so far all focus on the patient-what is thought to be best for the patient or respectful of the patient's preferences (even if conflict is possible between these measures). However, an additional measure of improved experience of death and dying in 2010 emphasises effects on family members (pp. 3, 5). It speaks of seeking 'lasting positive memories for family members after

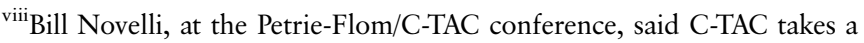
'neutral position' on PAS because there is so much controversy about it that it may interfere with their 'larger agenda'. See video, accessed July/
}

their loved ones have died' (p. 7) independently of whether patients have this as one of their preferences. Indeed, a diagram providing a new model of planning care lists bereavement support for the family after the patient's death (p. 13). This is another way in which it is suggested that EOL experience can be improved independent of merely following patients' preferences. Hence, the way is open for possible conflict between patients' preferences and their family's comfort. ${ }^{\text {ix }}$

It is already well known that despite a person's having signed an organ donor card, doctors have often gone to family members to ask permission to take organs and desisted when they refused. It is not clear why family members should have such control and a recommendation like 2010's to attend to the comfort of family members after their relative has died should not support such practices. Indeed, it should be possible for someone to place legal restrictions on family members overriding his wishes. There is a problem with this, however. In suggesting topics for a conversation with relatives, TCP asks: 'Are there any disagreements or family tensions that you are concerned about?' (p. 4) and C-TAC notes that increasingly family members are involved in providing EOLC (p. 4). While it is expected that conversations will smooth disagreements, there is a possibility that relatives will abandon a patient who insists on enforcing his preferences at odds with their own, once they find out his preferences in a TCP-recommended conversation.

So far, we can see that given what 2010 recommends, there are at least three standards for improvement in EOLC and experience: (a) satisfying patients' preferences; (b) satisfying such objective values as well-informed consent, less pain and suffering, exposure to best practices etc and (c) family positive reactions. There is a possibility of conflict among them that 2010 does not seem to recognise.

\section{E. Possible conflicts among cost-effective choices, distributive justice and beneficence}

Is there another possible standard for judging EOLC (which could lead to further possible conflict among standards)? 2010 emphasises that its proposals are not motivated by a desire to cut medical costs even though palliative and hospice care may cost less. However, it may seem that ensuring that patients are well informed about more cost-effective EOLC options (ie, ones producing greater benefits at lower cost) may lead to patient choices producing results that other countries try to achieve by public rationing (such as National Institute for Health and Care Excellence in the UK) to which there is often public resistance. However, rationing can often sacrifice benefits to those whose costs are cut. By contrast, 2010 claims that alternatives such as palliation and hospice can actually increase benefits to those whose costs are cut (eg, improve the quality of life and length of life). So there is said to be no conflict between reducing costs and increasing benefits.

Nevertheless, C-TAC emphasises that in its view when it comes to finances, changing $\mathrm{AC}$ and EOLC is a 'populationbased approach to care and coverage' (p. 24) involving 'population-based or value-based payments' (p. 25) and 'outcomes and successes are measured and valued at a population level rather than just service encounters between individual

${ }^{i x}$ Using family responses about end of life care (EOLC) as empirical evidence for how good the patient's EOLC was, as recommended by Dr Lachlan Forrow (see his videoed comments, accessed July/2016, at https://vimeo.com/175399098\#t=38m29s) may only work when 
clinicians and patients' (p. 9). The sense of 'value' in play here is important. For example, prominent palliative care proponent Dr Diane Meier (in a lecture at Mt. Sinai Medical School, 21 July 2016) used the formula Value $=$ Quality $/$ Cost (which she said now rules US government healthcare programmes) to evaluate the worth of palliative care. This is a cost effectiveness measure, but according to Meier, one could also directly read off of it ethical improvement: increasing quality represents increasing beneficence and decreasing costs represents more distributive justice (because money is not concentrated in one group where it does little good but is available for better use by others). However, it is not true that providing improved outcomes at lower cost is automatically a sign of more distributive justice or increased beneficence. This is because who gets the cost-effective outcomes is crucial for distributive justice and how much moral value an outcome has is crucial for beneficence.

According to many moral philosophers, known as prioritarians, there is greater moral value and increased distributive justice in giving at least some priority to helping those who would be among the worst off without help. ${ }^{\mathrm{x}}$ On this view, there could be greater moral value and more distributive justice achieved in giving even a smaller benefit at greater cost to those who would be worse off without help than in giving a greater benefit at less cost to those who would be better off even without help. For example, home palliative care might produce more improvement at less cost if (1) given to the rich and educated who also have a relative caretaker than if (2) given to the poor who have little education and are living alone. Yet distributive justice and beneficence might be better served in (2) than (1). Seeking the biggest improvement at the lowest cost may be a mark of value interpreted as efficiency but it is not necessarily a measure of value interpreted as beneficence or distributive justice. It would be unfortunate if this major point in moral philosophy were ignored by those involved in AC and EOLC projects. ${ }^{\mathrm{xi}}$

\section{F. Conversation versus written documents and advance versus current preferences}

The ultimate recommendations of 2010 are that there be AC planning consisting of more than a living will and involving meaningful conversations with patients: 'physicians...helping them understand their prognosis, explore options and evaluate the risks and burdens of their choices' (p. 19) and to 'reliably elicit patients' wishes' (Executive Summary). C-TAC emphasises helping patients clarify their own values and goals through reflection over time (p. 21), often revealing preferences they were unaware of before. 2010's listed goal to 'elicit patients' wishes' suggests others becoming aware of wishes the patient already knows he or she has, by contrast to TCP's suggestion that a patient may for the first time come to know his own preferences through reflection. A process that does the latter may actually bring people to have new preferences ${ }^{\mathrm{xii}}$ and one should be sure they are authentic and not instilled by others through a

\footnotetext{
${ }^{\mathrm{x}}$ Meier was not acquainted with this view.

${ }^{x i}$ For other moral criticisms of cost/effectiveness see Brock D. Ethical Issues in the Use of Cost Effectiveness Analysis for the Prioritization of Health Care Resources, in Bioethics: A Philosophical Overview ed. George Khusfh. Kluwer 2004 and Kamm FM. Cost Effectiveness Analysis and Fairness. J Pract Ethics 2015;3.

xii Richard Moran argues that finding out what you think about a certain matter is not usually about becoming aware of a belief you already had but about forming a new belief. Moran R. Authority and estrangement:
}

suggestive process. In addition, 2010 and C-TAC emphasise that the results of conversations and medical orders for lifesustaining treatment should be recorded, retrieved and respected by all caretakers. Conversations and recording of results are to be initiated earlier rather than later because patients may die much sooner than their own doctors predict (p. 12) and because of the benefits to be achieved by earlier commencement of palliation or hospice (if chosen).

While 2010, C-TAC and TCP all emphasise conversation with loved ones and professional caretakers, TCP seems to place less emphasis than the other two on creating a permanent and retrievable record of these conversations. This may be a crucial omission for though the project's title refers to 'the' conversation, TCP specifically says '...having the conversation isn't just a one-time thing. It's the first in a series of conversations over time' (TCP, p. 3). More than one conversation may be required with different people to clarify or change what was said first, to deal with questions that cannot be dealt with in one session. Though there is mention of someone being concerned about how he or she was interpreted and what people will remember of what he or she has said (p. 11), no mention at all is made of recording the conversations so that there is a permanent record.

In general, one might wonder why person-to-person conversations rather than only a written record of one's preferences are necessary with those who are not to be designated proxy decision makers. Perhaps conversation is emphasised because written prescriptions require too precise directives to be useful in changing circumstances whereas conversation allows communication of underlying values from which others can extrapolate decisions. ${ }^{\text {xiii }}$ However, a written record of underlying values is also possible independent of a conversation and decisions could be extrapolated from it. It is possible that back and forth conversation could lead to useful examination of one's preferences and presentation of more information bearing on them, perhaps leading them to change. Perhaps conversation is emphasised because ' $90 \%$ of people say that talking with loved ones about EOLC is important [though only] $27 \%$ have actually done so' (p. 2). However, these people may be wrong to think it is more important to speak to loved ones than to (a) write down either what one prefers or one's underlying values and to (b) make it legally impossible for loved ones to act contrary to these unless one wants them to have this option. However, without a legal restriction on loved ones' actions, an additional reason for having conversations appears: finding out if there will be opposition to one's wishes or underlying values and convincing loved ones not to override these.

2010, TCP and C-TAC all emphasise that conversations should begin well in advance of a decision time so that people have time to reflect and discuss issues. But this should not be interpreted to mean that past preferences take precedence over a competent patient's current ones just because the former were the result of longer reflection and more conversation. So it is worth emphasising that if a patient is still competent at the time decisions must be made, his or her current wishes should take precedence over any past written or discussed ones. ${ }^{\text {xiv }}$ At the

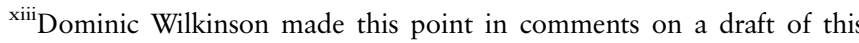
article.

${ }^{{ }^{x i v}}$ In TCP (p. 10), a distinction is drawn between an Advance Directive (AD) ('a document that describes your wishes') and a Living Will (LW) (specifying 'which medical treatments you want or don't want... if you are no longer able to make decisions on your own'). This implies that a person would be capable of overriding an AD but not a LW at the
} 
time a decision must be made, even patients whose wishes are clearly inconsistent with their past wishes and past (and even present) deepest values typically have their current wishes honoured out of respect for their personal sovereignty. The most famous cases of this sort involve Christian Scientists who request life-saving medical procedures contrary to their past instructions and deepest values.

\section{SECTION II}

Let us now consider two projects that can be seen as (in part) attempts to carry out recommendations like those in 2010 to engage in meaningful conversations that 'reliably elicit patients' wishes'. I will first consider TCP and then 2015 . $^{\mathrm{xv}}$

\section{A. The Conversation Project}

TCP's questions are intended for anyone, not only patients, to help prepare for and then actually have a conversation with someone else whom one either wants to (1) know one's preferences for one's EOL or (2) encourage to tell their preferences. As such, it is a population-wide effort not limited to clinical relationships. I will briefly examine some of TCP's preparatory questions and prompts and some actual conversation suggestions.

\section{What one most wants versus one's minimal requirements}

TCP first asks people to think about 'what matters to me at the end of life', saying this 'could help communicate... what abilities are most important to you-what's worth pursuing treatment for and what isn't' (p. 4). Unfortunately, the second quote contains much more than a clarification of the first. This is because failure to get 'what matters' or 'what is most important' does not necessarily imply that one would not want treatment and it would not be worth pursuing. The problem is that when people are asked what matters to them at the EOL they are probably thinking of goods they hope others will help them get, not the minimum without which they would not want treatment. For example, being with your child may matter to you at the EOL but this does not imply that if your child is not available then you would not want treatment. More careful phrasing is needed especially in introductory material for the general public.

\section{Preference for limited information versus well-informed involvement in decisions}

Some specific preparatory questions and prompts list possible answers on a scale (from 1 to 5). A set of answers is supposed to be the basis for deriving a more general conclusion-of which (as C-TAC suggests) one might not have previously been aware-about what one prefers. For example, for 'As a patient, I'd like to know' the answers range from 'only the basics' to 'all the details' (p. 4), and for 'If I had a terminal illness, I would prefer' the answers range from 'not know how quickly it is progressing' to 'know...best estimation of how long I have to live' (p. 5). Since these prompts allow patients to choose how much information they want, they will not necessarily result in their being well informed. It thus goes contrary to 2010's call for

\footnotetext{
${ }^{\mathrm{xv}}$ TCP is located in Boston and Dr Lachlan Forrow, lead author of 2010, is an advisor to that project. The study in 2015 was undertaken at Beth Israel Hospital in Boston where Dr Forrow is in charge of the EOLC programme. When I asked him what questions are used with patients in his programme, he referred me to 2015 so it is possible that the questions in 2015 are used in that hospital. They were also the questions used by Ariadne Labs (see ref. ${ }^{7}$ ), a project founded by $\mathrm{Dr}$
}

well-informed consent but it is consistent with one interpretation of 2010's call for following a patient's preferences, here applied to preferences for amount of information. This makes clear how the two strands in 2010 can come apart.

Between these two prompts is 'As doctors treat me, I would like' with the answers ranging from ' $\mathrm{My}$ doctors to do what they think best' to 'To have a say in every decision'. Following these three prompts, the TCP asks, 'Look at your answers... what kind of role do you want to have in the decision-making process?' It may become clear to someone that 'having a say in every decision' is problematically conjoined with declining best information about one's condition. Thus, it could be a useful point of this exercise to clarify preferences so that their consistency or inconsistency is clear.

\section{Imprecision and nudging versus reliably eliciting preferences}

Some concerns about the next set of questions are imprecision and whether there is nudging by the use of non-neutral questions. ${ }^{x i}$ The distinctive idea behind nudging is that there is a bias introduced in one direction, though people remain free to ignore it and move in another direction at relatively low cost. However, the nudge is introduced because it is assumed that there is 'status quo bias': people are more likely to move in the direction of the bias. Imprecision and nudging could interfere with reliably eliciting people's wishes as recommended in 2010.

For the preparatory question 'How long do you want to receive medical care?', \#1 on the answer scale is 'Indefinitely, no matter how uncomfortable treatments are' and \#5 is 'Quality of life is more important to me than quantity'. This seems to be a 'trade off' question whose assumptions are that someone wants some medical care that can extend quantity of life and that the most uncomfortable treatment translates into the lowest quality of life. A person who chooses \#1 would presumably agree that 'Quantity of life is more important to me than quality' (the contrast to \#5) but \#1 also suggests 'No reduction in quantity is worth an increase in quality', and the opposite to this is 'No reduction in quality is worth an increase in quantity' (which is stronger than 'quality is more important to me than quantity'). Again, more precision in phrasing seems advisable when dealing with matters of life and death in EOLC discussions.

There is nudging in the question dealing with comparable subject matter suggested for the actual conversation: 'When would it be okay to shift from a focus on curative care to focus on comfort care alone?' (p. 9). This question presupposes it would be okay to shift at some point and while someone may say 'never', there is a bias in favour of shifting introduced by the question. By contrast, 'Would it ever be okay to shift...?' would be a neutral (unbiased) substitute question that also more clearly allows for 'treatment indefinitely', which was the first possible answer to the preparatory question (we examined earlier).

Other sets of questions and prompts whose specifics I omit for reasons of space raise similar concerns. But it is worth nothing that there seems to be a mismatch between the first question in the set dealing with loved ones, 'How involved do you want your loved ones to be', and the possible answers to it, which focus on whether you want loved ones to do what you

${ }^{\text {xvi }}$ To use the phrase made famous by Thaler RH and Sunstein CR in Nudge: Improving Decisions About Health, Wealth, and Happiness. Penguin Books 2009. Unlike these authors, I do not consider persuading 
have said or what brings them 'peace'. Deciding what you want loved ones to do is not an answer to the question of how involved' you want them to be (since doing everything you want could still make them very involved).

\section{B. The Serious Illness guides}

2015 can be seen as another attempt to carry out recommendations like 2010's to engage in meaningful conversations to 'reliably elicit patients' wishes' based on information about prognosis and options for further care. ${ }^{\text {xvii }}$ The study constructed and used (1) a Serious Illness Conversation Guide (henceforth SICG) for use between doctors and patients with a family member or other support person (see figure 1 in 2015) and (2) a preconversation list of questions (henceforth Pre) that patients should consider before the conversation (see figure 5 in 2015). The questions in Pre do not correspond exactly to those in SICG though they do bear on them. (It would be good to know why patients are not asked to reflect on the SICG's actual questions.) 2015's SICG is identical with the SICG developed by Ariadne Labs (dated 22 May 2015). ${ }^{7}$ Ariadne Labs is a project with which Dr Atul Gawande, one of the coauthors of 2015 (and the author of Being Mortal, Henry Holt \& Co. 2014) is affiliated. Let us now consider the study in more detail.

\section{Nudging versus neutral questions}

Do Pre questions 'reliably elicit patients' wishes'? One concern is that phrasing nudges people to answer in a particular way and so may introduce a bias. Consider some questions: (a) 'What are you afraid of about your illness?' is used rather than 'Are you afraid of anything about your illness?' The first question assumes that there is something you are afraid of, so you may be less likely to answer 'nothing'. The second question is neutral. (b) 'What kinds of medical care do you not want?' is used rather than 'Are there kinds of care (medical or non-medical) that you do not want?' Because the first question assumes that there are kinds of care (and that these are medical) that someone does not want rather than being neutral about this, it might make it less likely for someone to say 'none'. That there is a nudging effect is only a hypothesis but since the questions are so easily made neutral that could be done without testing the hypothesis.

\section{Nudging, imprecision and possible framing effects of questions}

The questions in SICG evidence the same sort of nudging as well as some imprecision and 'framing effects'. These problems could interfere with the aim of 'reliably eliciting patients' wishes'. Consider these questions: (a) 'What are your biggest fears and worries about the future with your health?' is used rather than 'Do you have fears and worries about the future with your health?' The first question presupposes that there are biggest (and presumably big) fears and worries whereas the second question does not. (b) 'What abilities are so critical to your life that you can't imagine living without them?' is used rather than 'Are there abilities so critical to your life that you can't imagine living without them?' Because the first question assumes there are such critical abilities rather than being neutral as to whether there are any, it may nudge toward the view that mere time alive is not enough. This question is also imprecise in not distinguishing living without certain abilities long term (which one might reject) from living without them short term to get more adequate long term life. (Alternatively, one might

${ }^{x v i i}$ I shall consider it at some length because (unlike TCP) it is a reject living short term without certain abilities if this is all the time one will have but be willing to live without them long term because more time compensates for their absence.) More precision in this question (or additional follow-up questions) seems crucial to avoid mistakes in EOLC decisions.

The next question in SICG raises an issue that would be harder to fix: (c) '...how much are you willing to go through for the possibility of gaining more time?' According to behavioural economists Kahneman and Tversky, people will do more to avoid losses than to acquire gains even when the loss or gain would leave them in the same absolute position. Hence 'framing' a question as acquiring a gain rather than as avoiding a loss (or vice versa) can lead to what is known as a framing effect. $^{9}$ The question in the SICG is framed as a 'gain' and so people may not be willing to go through as much as if the question were framed as a 'no loss' (eg, 'How much are you willing to go through to avoid the possibility of losing more time?'). Avoiding this possible framing effect is not easy since there does not seem to be a version of the question that is neutral between the gain and loss frames. It may be worth first asking the question in the two different ways to different audiences to see if a difference is produced by the frames. If there is, it may be worth asking the same person the gain and loss versions at different times and averaging results if there are different responses. (Then the issue is whether there is a 'real' answer that has been elicited.)

Question (c) is also imprecise because no specific amount of time to be gained is mentioned; how much one might be willing to go through could depend on how much time is at stake. In addition, no quality is attached to the time so it seems that 'mere time' is at issue regardless of quality. Given that the preceding question asked what abilities one could not live without, responders may be primed to think that 'mere time' cannot be that important or, alternatively, to assume that the time at issue in question (c) has those critical abilities. It is possible that the question is meant to trigger further 'meaningful discussion' that will resolve these issues but if not, the question should be made more precise.

In the same vein, there is no explicit recommendation in SICG to 'push back' or investigate with the patient the reasons for their views about (a) fears, (b) critical abilities or (c) tradeoffs for more time; perhaps it is assumed the questions and answers will trigger more discussion. Suppose a patient said it was critical that he or she still be able to run a $3 \mathrm{~min}$ mile, that his or her greatest fear was having to visit a doctor 10 times, and that he or she would not be willing to trade an evening at the ballet for a year of life. Without doubting this person's legal competence, it would be odd to merely take such preferences at face value and act in light of them.

\section{Preferences for amount of information versus being well informed.}

Both Pre and SICG begin with questions about patients' knowledge of their illness and prognosis. However, rather than doctors 'helping them understand their prognosis' in a way that requires that they be well informed as 2010 recommends, SICG asks, 'How much information [about illness and prognosis]... would you like from me?' It directs interviewers to 'Share information, tailored to information preferences' of the patients. (The corresponding Pre question asks, 'What information would you want to help make decisions?') As in TCP, the goal is following patients' preferences for information rather than ensuring a well-informed patient. So, while it is consistent with one 
not meet 2010's (possibly philosophically conflicting) focus on well-informed consent. Patients may choose not to get information about prognoses that they would need in making decisions even if they have full information about care options. (PEACEto which 2015 refers and which I shall discuss further belowsays: '...patients who have unrealistically positive views of their prognosis tend to choose invasive measures...instead of care directed at comfort...patients are the best individuals to make decisions for their care based on their personal values when they have accurate knowledge about prognosis. Therefore, prognosis communication has become a focus of palliative care', p. 2509. $)^{\text {xviii }}$

\section{Enhanced role of professionals and conditional versus unconditional commitment}

The SCIG that I have just discussed underwent changes and a 'Redesigned Serious Illness Conversation Guide' (henceforth 2016) is posted at the Ariadne Labs website (dated 9 March 2016) along with a conversation about it with Dr Susan Block. ${ }^{8}$ It is said to be 'the centerpiece of our Serious Illness Care Program' (p.2) and that 'using the guide-as written-leads to rich, meaningful discussion with...patients' (p. 4). The question concerning provision of information, one of whose aims is to 'assess...information preferences', is still 'How much information... would you like from me' and the directions to the professional in sharing prognosis are still to 'tailor information to patient preferences'. The questions concerning fears, critical abilities and what one is willing to go through to get more time are also unchanged and so still are imprecise and possibly nudging.

There is one new question: 'What gives you strength as you think about the future with respect to your illness?' It is phrased non-neutrally by contrast to 'Is there something that gives you strength?' In addition, the interviewer is now not only to ask questions but in concluding (a) show her understanding of what the patient has said and (b) affirm her commitment to the patient by saying 'We're in this together' (p. 2).

A third important addition coming between (a) and (b) has the professional say, 'given your goals and priorities and what we know about your illness...I recommend' (p. 2). No longer is the patient alone to combine his or her knowledge of his or her illness and options with his or her values and goals. The professional is given a role in doing this. However, given that the information provided to the patient about his or her illness will have been tailored to patients' preferences, it is not clear whether 'what we know' here involves the best information available (presumably known by the professional) or only what the patient knows. But it is clear in what is said that it is the patient's goals and priorities that the professional should use to derive a recommendation. Since the recommendation is not an order the patient may reject it, and this raises a question about the concluding interviewer statement 'We're in this together' which is said to 'affirm your commitment to the patient'. Is 'we're in this together' contingent on the patient having accepted the recommendation? If not, concern that there will be

\footnotetext{
xviii2015's own study procedure raises a question about informed consent. Under the topic of 'Ethics' it says that it has participants' informed consent to the study (p. 12). But it also says: "we measure depression...If the patient answers 'more than half the days' or 'nearly every day' to the question, 'Thoughts that you would be better off dead, or hurting yourself?'...we notify the patient's NP or physician" (p.12). Were patients informed before participating that this would happen as, I
}

no commitment unless the patient accepts the recommendation could be avoided if the commitment were made before and not (as currently) after giving the recommendation.

\section{5a. Dignity versus peacefulness?}

While 2016 gives the professional an enhanced role it confines her or him to working within the values of the person deciding on care. Presumably this includes the person's views about what is a good death and EOL. However, other aspects of 2015 and PEACE do not seem to accept such restrictions as we shall now see. 2015 describes the goal of its SICG as '...to optimise the alignment between patient goals and medical care....and to enhance quality of life and peacefulness' (p. 2); and it says of its research that 'the primary outcomes of the trial are patient receipt of goal-concordant care and peacefulness at the end of life' (p. 7). 'Peacefulness' seems to be a psychological state, not merely absence of physical suffering and it is here listed as a good independent of achieving the patient's goals. Something can be good either in itself or for the sake of something else (instrumentally) and some things can be both. Peacefulness seems to be thought of as good in itself in 2015. (As we shall see, it seems to be thought of as both types of good in PEACE.)

Is it always an appropriate goal to seek peacefulness as an end in itself? Recall that 2010 began by emphasising that there was variation in belief about how to deal with death and dying and that was the reason it gave for the patient's own preferences and values having a dominant role in determining care. This variation in beliefs may apply to whether peacefulness at EOL is always appropriate. After all, Dylan Thomas wrote, 'Do not go gentle into that good night./Rage, rage against the dying of the light'. ${ }^{10}$ Further, if one has lived incorrectly, it might be appropriate to struggle with this at the EOL (as Ivan does in the Tolstoy novella The Death of Ivan Ilych), foregoing peacefulness in most of one's final phase. ${ }^{\text {xix }}$ And if one believes punishment after death will come for wrongs one has done, it might also be appropriate not to be peaceful at the end of one's life.

My assumption here is that 'appropriateness' of response is a matter of reasonableness of response and that is not determined solely (or at all) by whether the response has good consequences for oneself. Rather it is determined by the 'fit' between one's past (good or bad life) or future (eg, non-existence, heaven or hell) and the response to it. Furthermore, choosing a belief system (eg, there is no hell for sinners) or way of reflecting on one's life on the basis of whether it allows for a peaceful end might conflict with the claim in 2010 that 'What people want and need as the end of life approaches...that their dignity is maintained' (p. 2). ${ }^{\mathrm{xx}}$

It is not clear what a person's dignity is and whether it is to be 'maintained' or rather respected. ('Maintained' suggests it could be lost, eg, by occupying an 'undignified' posture or through disrespectful treatment. By contrast, that the dignity of the person should be respected does not imply that it can be lost if it is not respected or that respect is needed to maintain it. $\left.{ }^{x i}\right)$ One possibility is that a person's dignity is related to his or her capacity to form beliefs and decide on conduct on the basis of reasons. This is presumably why palliative caregivers try

\footnotetext{
xix I discuss the novella in Kamm FM. Rescuing Ivan Ilych: How We Live and How We Die. Bioethical Prescriptions. Oxford University Press, 2013.

${ }^{x x}$ Beth Israel Hospital's Know Your Options leaflet for patients also says '...working to ensure your comfort and dignity'.

${ }^{x x i}$ For discussion of different views of dignity, see Rosen M. Dignity: its
} 
to provide reasons for being at peace rather than merely injecting someone with a drug that would render him or her peaceful. However, philosophers distinguish (i) the reasonableness of a belief which has to do with whether there is adequate support for its truth and (ii) the reasonableness of making oneself believe something (even something unreasonable) because doing so would be in one's self interest (eg, taking a drug to believe that $2+2=5$ because someone will kill you unless you believe it). Making oneself have beliefs and attitudes that promote peacefulness rather than having beliefs and attitudes that are grounded in the truth of their content (and to whose truth peacefulness may be a reasonable response) seems inconsistent with a certain conception of dignity. It is possible that comfort should take precedence over dignity (so-conceived) but then one may have to rethink one's commitment to dignity.

\section{b. Professionals' conception of a good death versus patients' conceptions and rights}

Suppose some professionals in EOLC believe a good death is a peaceful one and aim at this in using the SICG (as 2015 states). Then they would come to their mission with a particular view of what makes a good death and not be neutral among a variety of views. This raises the following issues. (1) As noted, 2016's revisions to the 2015 SICG has the professional say 'given your goals and priorities and what we know about your illness...I recommend'. It does not say 'given your goals and priorities and my aim of achieving a peaceful death for you...I recommend'. So the revised SICG gives the impression that any non-neutral view that the professional has about a good death will not play a role in the recommendation. If this is not so, then the phrasing should be changed for the sake of transparency to make clear that the professional's view is being incorporated (although this may raise the problem of nudging by the professional's authority).

(2) Suppose professionals make clear to those they are advising that they believe a good death (or dying experience) involves peacefulness and they aim to convince the person of this by evidence and conversation. This is not appropriately considered nudging. It is also consistent with their respecting and acting on the wishes of people who continue to adhere to different views. ${ }^{\text {xii }}$ This could be because professionals recognise that their holding one view does not necessarily make it more reasonable than someone else's. However, sometimes their ground for giving priority to another's wishes may have to be rights-based, namely that even if a person's views are idiosyncratic and not as reasonable as the professional's the person could be legally competent to have final say over whether his or her EOL will be peaceful, and it could be wrong not to remain committed to helping him or her. (Note that the rights-based ground seems stronger than the ground given in 2010 for 'patient-centeredness'.)

There may be reasons for not acceding to people's preferences and values (such as economic constraints on funding or the responsibility of people to be well informed) and it may be permissible to question people about the reasonableness of their choices. However, that professionals have a particular (controversial) view about what is a good EOL does not by itself seem to be sufficient reason for not acceding to people's preferences about EOLC.

xxii
SECTION III

\section{A. EOLC and emotional versus mere cognitive acceptance}

2015's discussion of peacefulness makes reference to PEACE, a study of different responses to knowledge of impending death that can help us to better understand some professionals' conception of a good death. PEACE begins by distinguishing between mere cognitive awareness of one's prognosis, the sort of understanding of information that 2010 emphasises, and emotional response to that information. It claims that one possible emotional response is an 'existential crisis' as 'patients review their lives in light of illness and impending death' (p. 2510). It distinguishes two particular types of responses (called 'adjustments', p. 2515): (1) One type, called 'peaceful acceptance' (Acceptance), is described in the words of Erik Erikson as involving 'confronting one's own mortality--with integrity....an informed and detached concern with life itself in the face of death...finding meaning at the end of life (EOL)... maintain their sense of dignity' (p. 2510); it is seen as the 'final stage of human development (typically occurring in late adulthood)' (p. 2510). (2) The second type of adjustment, called Struggle, involves 'despair, fear, and foreboding, injustice, anger... and the sense of a foreshortened future' (p. 2510) and is more frequent in younger patients (p. 2515).

The purpose of the study was to see the relation between Acceptance or Struggle and EOLC outcomes, in particular the relation to 'location of death and use of invasive measures at the EOL' (p. 2510). However, the authors also say, 'This construct [Acceptance/Struggle]...may be an important target for clinical interventions aimed at improved well being at the EOL' (p. 2515). This might imply that Acceptance or Struggle in itself is a component of well (or ill) being independent of its effects. This would represent a view about the intrinsic value of these adjustments. Alternatively, it may merely involve judging the value of the effects of Acceptance or Struggle (eg, certain locations of death and use of non-invasive means) as in themselves components of well-being at the EOL with Acceptance or Struggle having only instrumental value or disvalue.

\section{B. The contents of Acceptance and Struggle as the study describes them.}

(1) Does peacefulness require detachment?

Acceptance involves a 'detached' attitude to one's illness and death, suggesting that one does not focus on 'personal' loss to oneself (one is detached). But suppose that unexpectedly a good chance of long-term, high-quality survival returned. Presumably one would seek out the chance not because it was a good thing to happen from a detached (or impartial) perspective but because it involved avoiding a personal loss. Such a switch in perspectives might suggest that the detached attitude was only what is referred to as an 'adaptive preference', a comforting way of dealing with outcomes by seeing 'sour grapes' in what one cannot have. Some might argue that a correct perspective on life should be constant though different circumstances, either detached or personal or some combination. And if one adopts the detached view only to get comfort, how does it represent 'confronting one's own mortality-with integrity' (p. 2510)? A better (re)descrption of Acceptance might be 'a nondetached point of view that acknowledges personal loss but still allows for emotional acceptance'.

\section{(2) Acceptance of imminent death versus acceptance of probable} death

'Acceptance' is reserved for acceptance that death is certainly imminent but there could be peaceful acceptance of the high 
successful life-extending treatments. Having hope only in proportion to its reasonableness is also acceptance though it would not necessarily reduce an accepting person's use of expensive technologies with little probability of success. The ball would be in society's court to deny, perhaps on cost effectiveness grounds, means it would not be unreasonable for such an accepting individual to choose.

\section{(3) Acceptance of unfairness and appropriate struggle and fear}

(a) As noted, PEACE finds Struggle more prevalent among younger people dying 'before the age-appropriate time of confronting death' (p. 2515). Perhaps then Struggle in younger people is not age-inappropriate and could be consistent with their integrity even within the researchers' own framework.

(b) With respect to the fear, foreboding, sense of unfairness and anger said to characterise Struggle: (i) If one believed that death involved an afterlife where one would be punished for one's wrong acts, fear and foreboding could appropriate at any age. Only a denial of the reasonableness or correctness of a particular belief system-which is not supposed to be a part of the approaches I am considering-could imply that such fear and foreboding were unreasonable. (I have already argued that the reasonableness of a belief system is not judged by whether it disturbs one's peace.) (ii) However, fear might reasonably vary with age if the old need not but the young can fear that they will have had very little time in their life. (If one is certain that one will have had very little time, one may not 'fear that' one will have had little time because that phrase expresses uncertainty. But this is compatible, I think, with 'fear of' the meagerness of one's life itself.) (iii) It is also possible to believe that one's dying young when others do not is 'cosmically' unfair without reacting with anger to this; one could have an accepting attitude to unfairness or injustice. There is no necessary connection between an accepting attitude and the object of the attitude (which could be unfairness, a belief in which 2015 claims accompanies only Struggle).

\section{Problems of aiming at peaceful acceptance, non-invasive means and spirituality}

Now given PEACE's conception of Acceptance, consider its ultimate conclusions: To improve well-being (an intrinsic good) in EOL one should seek (peaceful) Acceptance in patients. A prominent effect of Acceptance, the study says, is less use of invasive measures (eg, feeding tubes) in EOL, while there is increased use of invasive measures with Struggle (p. 2515). One interpretation of this is that not using (even minimally) invasive means is itself considered a component of well-being and an improvement in EOLC. But why is this true if the invasive means are life sustaining and not major impositions on other activities?

With respect to caregiver action, PEACE says, 'If acceptance and struggle...change over time, then they also may be targets for interventions to improve EOL care...This construct [Acceptance/ Struggle]...may be an important target for clinical interventions aimed at improving well being at the EOL' (p. 2515). A prominent cause of Acceptance, it is reported, is a patient's sense of being 'highly spiritual' (p. 2515), though no details are given about what this spirituality involves. With respect to caregiver action this could imply that 'interventions' should be aimed at making people more spiritual because this would lead to Acceptance which would lead to reduced use of invasive means and hence, according to the study, a better EOL.

It seems that adding 'peacefulness' as an independent factor worth achieving either intrinsically or instrumentally might lead (because there are varying opinions about good EOL (2010)) to adopt different aims. In particular, the aim of encouraging a particular world view or way of approaching reality (high spirituality) as a means to further a particular view of a good EOL and good EOLC (eg, peacefully and with no invasive means such as feeding tubes). I think such a change in aims is a matter for concern.

If evidence showed that mere knowledge of one's prognosis and options led to patients choosing the professionals' preferred EOL, patient knowledge and choice would be vindicated as a means to what professionals view as the best EOL (though they would not necessarily be valued for their own sakes). However, according to PEACE, mere cognitive awareness does not always lead to choosing its favoured EOL experience because Struggle can occur in response to knowledge. (Note that Acceptance (as PEACE understands it) and only non-invasive care are even less likely if patients are allowed to reduce the information they are given as in SICG (2015 and 2016) and so do not know how bad things are.) Some might see this as an argument for not providing information about invasive options or for society refusing to fund EOL invasive procedures. Rather than recommending such action, PEACE seems to suggest doing what will bring about the particular emotional adjustment (Acceptance) that will lead patients to choose its favoured EOLC. The problem is that this may require encouraging 'spiritual awakening' and such encouragement does not seem respectful of persons with different views.

\section{Assisted suicide and acceptable life to the end}

Finally, PEACE's discussion of Acceptance of, and Struggle with, illness and death is not supplemented by discussion of Seeking death (as in PAS). PEACE says: 'patients with higher symptom burdens...poorer functional status also had higher Struggle With Illness scores' (2515). This seems a reasonable patient response but one would have thought that in the absence of ability to lower symptom burdens and improve functional status, such patients might also want to be helped to seek death.

This brings us back to the declared aim of projects reported on in 2010, C-TAC and TCP, which is to make life up to death acceptable to the person living it. One participant in a Petrie-Flom/C-TAC conference spoke about having a last phase of life leading to death that would be like jumping off Niagara Falls, implying that she wanted to avoid a long period of decline or of being at a low point. ${ }^{11}$ However, this may not always be possible even if one avoids life prolonging treatment and uses effective palliative care. For according to the projects I have discussed, a person is to determine what an acceptable EOL is for him or her and this may involve much more than simply avoiding physical suffering (eg, meaningful projects). ${ }^{\text {xiii }}$ Persons not using life-support therapy cannot escape an unacceptable life so understood by being disconnected from life support (considered a form of letting die rather than killing). ${ }^{\text {xxiv }}$ Hence, a person's life may not end before it becomes unacceptable to him or her unless someone actually causes his or her death.

\footnotetext{
${ }^{x x i i i}$ For more on this issue see my 'The Purpose of My Death: Death, Dying, and Meaning' forthcoming in Ethics, April 2017.

${ }^{x x i v}$ Andrew Dreyfus at the Petrie Flom/C-TAC Conference discussed how his father ended his life when he felt he was 'fading' by having someone use a computer program to deactivate his heart pacemaker. (See video, accessed July, 2016 at https://vimeo.com/175399098.) This is an interesting form of ending life support since it involves stopping something that has become part of someone's body. It is not clear that it differs from stopping any other internal organ if this could be done in the same way. Hence, it is close to killing someone not dependent on
} 
One may argue that inducing death differs from ending life support because only if life support is not ended will there be an imposition on someone's body contrary to his or her wishes. It is debateable whether this is a difference that morally rules out inducing death. ${ }^{\mathrm{xxv}}$ My concern now is only that those who support the aims of 2010, TCP and C-TAC (i) do not oppose people ending life-saving treatment with the intention of avoiding what is a personally unacceptable life though it does not involve irremediable physical suffering, ${ }^{\mathrm{xxvi}}$ (ii) they also want active interventions that will make life not unacceptable to the person whose life it is and (iii) there are those, such as Atul Gawande (a coauthor of 2015), who favour active intervention with PAS to end irremediable physical suffering, ${ }^{12}$ implying the view that intentionally inducing death is not always a moral barrier to ending life. Holding these three views suggests that one should also favour allowing PAS so that someone can avoid an EOL he or she finds unacceptable even if it does not involve irremediable physical suffering. ${ }^{\text {xxvii, }}$ xxviii

\footnotetext{
${ }^{\mathrm{xxv}}$ See my discussions of assisted suicide reprinted in my Bioethical Prescriptions. Oxford University Press, 2013.

${ }_{\text {xxvi See generally Being Mortal. }}$

${ }^{x x v i i}$ I provide a more complete argument for this conclusion (based on an argument for PAS in my 'Four-Step Arguments for Physician-Assisted Suicide and Euthanasia' (reprinted in Bioethical Prescriptions)) in "Doing Death: Public Policy, Law, and the Ethics of Physician Assisted Suicide" (unpublished).

xxviii I am grateful to Dr. Lachlan Forrow for directing me to many of the documents I discuss and for his comments on an earlier draft. I thank Dr. Dominic Wilkinson, an anonymous reviewer for the Journal of Medical Ethics, and Professor Glenn Cohen and his students at the Harvard Law School seminar on Bioethics for comments on an earlier draft. Work on this article was supported by the Petrie-Flom Center for Health Law Policy, Biotechnology, and Bioethics at Harvard Law School.
}

Competing interests None declared.

Provenance and peer review Not commissioned; externally peer reviewed.

\section{REFERENCES}

1 Coalition to Transform Advanced Care (C-TAC). The Advanced Care Project, p. 4. http://www.thectac.org/wp-content/uploads/2015/06/ACP-Report-6-18-15-FINAL.pdf (accessed Jul 2016).

2 C-TAC, p. 17.

3 Forrow L, Conway J, Kim D, et al. Patient-Centered Care and Human Mortality: The Urgency of Health System Reforms to Ensure Respect for Patients' Wishes and Accountability for Excellence in Care. October 2010. http://molst-ma.org/sites/molst-ma.org/files/2010ExpPanRep.pdf (accessed Jul 2016).

4 The Conversation Project and the Institute for Healthcare Improvement. Your Conversation Starter Kit. http://theconversationproject.org/wp-content/uploads/2015/ 11/TCP_StarterKit_Final.pdf. I use "TCP" to refer to this document but also to the project itself (accessed Jul 2016).

5 Bernacki R, Hutchings M, Vick J, et al. Development of the Serious Illness Care Program: a randomized controlled trial of a palliative care communication intervention. BMJ 2015;5:e009032.

6 Mack JW, Nilsson M, Balboni T, et al. Peace, Equanimity, and Acceptance in the Cancer Experience (PEACE), validation of a scale to assess acceptance and struggle with terminal illness. Cancer 2008;112:2509-17.

7 Ariadne Labs SCIG. http://www.ct.gov/dph/lib/dph/molst/042715_most_serious_ illness_conversation_guide.pdf (accessed Jul 2016).

8 https://www.ariadnelabs.org/2016/03/09/redesigned-serious-illness-conversationguide-supports-more-better-and-earlier-conversations-about-what-matters-most/ (accessed Jul 2016).

9 Kahneman D, Tversky A. Prospect theory: analysis of decisions under risk. Econometrics 1979;47:263-91.

10 Thomas D. Do not go gentle into that good night. In Dylan Thomas, Dylan Thomas Selected Poems 1934-1952, New Directions, 1952, p. 122.

11 Amy Berman in Petrie-Flom/C-TAC video. https://vimeo.com/175399097\#t=11m55s (accessed Jul 2016).

12 Gawande A. Being Mortal: Medicine and What Matters in the End. Henry Holt \& Co. 2014 ; p. 245. 